\title{
Influência do Manej o da Palhada de Capim-Braquiária (Brachiaria decumbens) SOBRE O DESENVOLVIMENTO INICIAL DE SOJ A (Glycine max) E AMENDOIM-BRAVo (Euphorbia heterophylla) ${ }^{1}$
}

\author{
Influence of Straw Management of Brachiaria decumbens on the Initial Development of \\ Glycine max and Euphorbia heterophylla
}

\author{
MACIEL, C.D.G. ${ }^{2}$, CORREA, M.R. ${ }^{2}$, ALVES, E. ${ }^{2}$, NEGRISOLI, E. ${ }^{2}$, VELINI, E.D. ${ }^{3}$, RODRIGUES, \\ J.D. ${ }^{4}$, ONO, E.O. ${ }^{4}$ e BOARO, C.S.F. ${ }^{4}$
}

\begin{abstract}
RESUMO - Com o objetivo de avaliar os efeitos de diferentes manejos de palhada de capimbraquiária sobre o desenvolvimento inicial da cultura de soja e da planta daninha amendoim-bravo, foi conduzido um experimento em condições de casa de vegetação no NuPAM-FCA/UNESP, Botucatu-SP. Os tratamentos utilizados foram: manejo da palhada na superfície do solo + irrigação superficial (T1); manejo da palhada na superfície do solo + irrigação subsuperficial (T2); palhada incorporada ao solo (T3); e testemunha sem cobertura (T4). A palhada foi colhida no campo 30 dias após dessecação com o herbicida glyphosate $\left(1,44 \mathrm{~g}\right.$ i.a. $\left.\mathrm{ha}^{-1}\right)$. O delineamento experimental utilizado foi o inteiramente casualizado, com sete repetições, sendo as unidades experimentais vasos plásticos, com a soja e o amendoimbravo semeados paralelamente, em linhas distintas. O T1 reduziu significativamente o índice de velocidade de germinação (IVG) e a altura das plântulas de soja aos 5 e 10 dias após a emergência (DAE), ao contrário do amendoim-bravo, o qual não sofreu interferência dos tratamentos estudados, constituindo-se em uma planta-problema para sistemas produtivos com palhada de capim-braquiária. Os resultados da análise de crescimento (TCA - taxa de crescimento absoluto, TCR - taxa de crescimento relativo e TAL - taxa de assimilação líquida) das plântulas de soja e amendoim-bravo apresentaram valores máximos aos 15 DAE, com exceção do T3 para soja, o qual reduziu expressivamente o desenvolvimento em relação aos demais tratamentos.
\end{abstract}

Palavras-chave: palhada, plantio direto, planta daninha.

\begin{abstract}
An experiment was carried out under greenhouse conditions at NuPAM-FCA/UNESP, Botucatu, SP, Brazil to evaluate the effects of different types of straw management of Brachiaria decumbens on the initial development of Glycine max and Euphorbia heterophylla. The treatments were: straw on soil surface + irrigation on the top (T1); straw on soil surface + underirrigation (T2); straw incorporated into the soil (T3) and control (T4). B. decumbens straw was collected in the field thirty days after glyphosate application (1.44 g i.a. $\mathrm{ha}^{-1}$ ). The experimental design was completely randomized with seven replications, with the experimental units consisting of plastic pots, where G. $\max$ and E.heterophylla were sown in parallel lines. T1 reduced significantly the germination speed index (GSI) and G. $\max$ plant height at 5 and 10 days after emergence (DAE) while $\boldsymbol{E}$. heterophylla did not suffer interference of the treatments, being a problem for cropping systems involving B. decumbens straw. Growth analysis data (AGR absolute growth rate, RGR - relative grotw rate and NAR - net assimilation rate) on $\mathbf{G}$. $\max$ and E. heterophylla presented maximum values at 15 DAE, except for T3 with G. max, which presented expressive decrease in its initial development, compared to the other treatments.
\end{abstract}

Key words: straw, no-tillage, weed.

Recebido para publicação em 1.3.2002 e na forma revisada em 12.12.2003.

2 Alunos de Pós-Graduação em Agricultura da FCA/UNESP; ${ }^{3}$ Prof. Dr. do Dep. de Produção Vegetal da FCA/UNESP, Caixa Postal 237, 18603-907 Botucatu-SP; ${ }^{4}$ Prof. Dr. do Dep. de Botânica IB/UNESP, Caixa Postal 18, Botucatu-SP.

Planta Daninha, Viçosa-MG, v.21, n.3, p.365-373, 2003 


\section{INTRODUÇÃO}

O cultivo da soja em área de reforma de pastagens degradadas vem se concretizando em muitas regiões brasileiras, principalmente nos Estados do Mato Grosso, Mato Grosso do Sul e Paraná. No entanto, vários são os relatos de agricultores descrevendo efeitos como redução de crescimento, amarelecimento e diminuição na produção da cultura da soja, em conseqüência da incorporação de palhada de pastagens de Brachiaria decumbens ao solo pelo sistema de plantio convencional. Esse fato não é observado quando se adota o sistema de semeadura direta, utilizando-se palhada de $B$. decumbens como cobertura morta.

A alelopatia - definida como o efeito inibitório, direto ou indireto, de uma planta sobre outra - ocorre pela produção de compostos químicos liberados ao meio. Esse fenômeno ocorre em comunidades naturais de plantas (Gressel \& Holm, 1964) e pode também interferir no crescimento das culturas agrícolas (Muller, 1966; Bell \& Koeppe, 1972). Provavelmente, as conseqüências mais significativas da alelopatia assumem grande importância quando resíduos de vegetais são deixados sobre a superfície ou incorporados anualmente ao solo (Guenzi et al., 1967).

Compostos químicos resultantes da decomposição de resíduos vegetais sobre a superfície ou misturados na camada arável do solo têm sido registrados por vários pesquisadores (McCalla \& Haskins, 1964; Patrick et al., 1964; Patrick \& Tousson, 1965; Patrick, 1971; McCalla \& Norstadt, 1974; Rice, 1984), que citam como sintomas a redução das plântulas, o encurtamento de entrenós, os caules delgados e contorcidos e o estande desigual e reduzido em condição de campo, especialmente nas áreas onde existe maior quantidade de resíduos vegetais.

Ramos \& Valente (1997) demonstraram, em laboratório, a interferência alelopática de $B$. decumbens na germinação de sementes de milho e soja. Almeida et al. (1986), estudando o efeito da incorporação de diferentes quantidades de matéria seca de capim-marmelada (B. plantaginea) no desenvolvimento de plantas de soja, verificaram redução de biomassa seca das raízes de $42 \%$ na concentração de $1 \%$ (p/p). No entanto, segundo os autores, os efeitos apenas se manifestaram nos primeiros 15 dias do desenvolvimento da soja, devido à rápida decomposição dos resíduos incorporados. Almeida (1988) também relata que a cobertura morta proveniente da dessecação com glyphosate a partir de quatro plantas de capim-marmelada $/ \mathrm{m}^{2}$ afetou a germinação e o desenvolvimento de plântulas de trigo. Durigan \& Almeida (1993) afirmam que os efeitos alelopáticos provocados pela incorporação de resíduos vegetais ao solo são muito variáveis. Normalmente os resíduos secos originam fitointoxicação severa e duradoura, principalmente em baixa temperatura. Os efeitos fitotóxicos da incorporação do material vegetal são transitórios, ocorrendo apenas quando as raizes das plantas no seu trajeto no solo entram em contato com o material incorporado.

Velini \& Negrisoli (2000), abordando o efeito da cobertura do solo e germinação de plantas daninhas, declararam que na maioria das situações as alterações nas comunidades infestantes têm sido atribuídas aos efeitos dos supostos efeitos alelopáticos, negligenciando os efeitos físicos das coberturas mortas, uma vez que a totalidade das espécies de plantas daninhas apresenta dormência ou algum tipo de controle da germinação.

Desse modo, o trabalho teve como objetivo determinar, por meio de índices de velocidade de germinação e análises de crescimento, os possiveis efeitos de diferentes manejos de palhada de capim-braquiária (B. decumbens) sobre o desenvolvimento inicial da soja (Glycine max) e do amendoim-bravo (Euphorbia heterophylla).

\section{MATERIAL E MÉTODOS}

O experimento foi desenvolvido em casa de vegetação, nas dependências do NuPAM (Núcleo de Pesquisas Avançadas em Matologia), pertencente ao Departamento de Produção Vegetal da FCA/UNESP, Botucatu-SP.

Os tratamentos utilizados foram constituídos por dois tipos de manejo da palhada de capim-braquiária, associados ao uso de irrigação superficial e subsuperficial, de forma a proporcionar uniformidade no umedecimento da palhada no primeiro caso e, no segundo, evitar o umedecimento direto da palhada 
disposta na superfície do solo. Dessa forma, entre os tipos de manejo da palhada de capimbraquiária foi utilizada cobertura morta disposta na superfície do solo e incorporada a $10 \mathrm{~cm}$ de profundidade. A dessecação do capim-braquiária foi efetuada utilizando-se glyphosate na dose de 1,44 g de i.a. ha ${ }^{-1}$, sendo a palhada coletada 30 dias após a aplicação do herbicida e submetida à secagem em estufa de aeração forçada a $65{ }^{\circ} \mathrm{C}$, por um período de 72 horas. O solo utilizado no experimento foi coletado da camada arável de Latossolo Vermelho-Escuro de textura média e peneirado em peneira de malha $5 \mathrm{~mm}$, sendo devidamente corrigido conforme as suas características químicas, as quais estão dispostas na Tabela 1.

O delineamento experimental utilizado foi o inteiramente casualizado, com quatro tratamentos e sete repetições. As unidades experimentais constituíram-se de vasos plásticos com $5 \mathrm{~kg}$ de solo, nos quais foi adicionada palha fracionada em partículas de aproximadamente $3 \mathrm{~cm}$, na proporção de $6.000 \mathrm{~kg} \mathrm{ha}^{-1}$ para os diferentes tipos de manejo, com exceção do tratamento testemunha, onde não foi utilizada cobertura do solo com palha. As sementes da soja cultivar IAC-19 e da planta daninha amendoim-bravo foram semeadas, paralelamente, em linhas distintas nas unidades experimentais, a uma profundidade de 3 e $1 \mathrm{~cm}$, respectivamente. A umidade do solo foi mantida em torno de $65 \%$ por meio de irrigações superficial e subsuperficial, conforme o tratamento, sendo controlada através da pesagem diária das unidades experimentais.

Foram efetuadas quatro coletas da parte aérea de uma planta de soja e duas de amendoim-bravo, intercaladas em intervalos de cinco dias. Ao final de cada período, os parâmetros inicialmente avaliados foram a altura das plantas $(\mathrm{cm})$ e o teor de clorofila $\left(\mathrm{g} \mathrm{dm}^{-2}\right)$, através de clorofilômetro portátil, modelo SPAD 502 (Minolta). Em seguida, a parte aérea total de ambas as espécies foi submetida à determinação de área foliar (AF), utilizando-se um integrador de área foliar, e, juntamente com os pecíolos e caules, acondicionada em estufa de secagem com aeração forçada a $65^{\circ} \mathrm{C}$ por um período de três dias, para determinação da matéria seca. A fase experimental foi encerrada 28 dias após a semeadura das espécies estudadas, ou seja, 20 dias após a emergência (DAE). Com base nos resultados de matéria seca e área foliar, foram determinadas as taxas de crescimento absoluto $\left(\mathrm{TCA}=\mathrm{g} \mathrm{dia}^{-1}\right)$, a taxa de crescimento relativo $\left(\mathrm{TCR}=\mathrm{g} g\right.$ dia $\left.^{-1}\right)$, a taxa assimilatória líquida $\left(\mathrm{TAL}=\mathrm{g} \mathrm{dm}^{-2} \mathrm{dia}^{-1}\right)$ e a razão de área foliar (RAF $=\mathrm{dm}^{-2} \mathrm{AF} \mathrm{g}^{-1} \mathrm{MS}$ ), tanto para a cultura da soja quanto para a planta daninha amendoim-bravo. Os resultados obtidos foram submetidos às análises de variância e regressão, com exceção da variável razão de área foliar (RAF).

Durante os primeiros dias após semeadura, foi efetuada a contagem do número de plântulas germinadas no dia, com a finalidade de estimar o índice de velocidade de germinação (IVG), conforme metodologia proposta por Maguire (1962).

Os resultados de IVG, RAF, altura de plântulas de soja e amendoim-bravo e teor de clorofila das folhas de soja foram submetidos à análise de variância pelo teste $\mathrm{F}$; as médias dos tratamentos foram comparadas pelo teste de Tukey a $5 \%$ de probabilidade.

\section{RESULTADOS E DISCUSSÃO}

O tratamento referente à associação de palhada de capim-braquiária na superfície do solo + irrigação superficial (T1) proporcionou redução significativa do índice de velocidade de germinação (IVG) para as plântulas de soja (Tabela 2). Entretanto, esse fato não foi constatado para a espécie amendoim-bravo (Tabela 3),

Tabela 1 - Características físico-químicas do solo utilizado como substrato no experimento. UNESP/Botucatu-SP, 2000

\begin{tabular}{|c|c|c|c|c|c|c|c|c|}
\hline M.O. & PH & $\mathrm{P}^{\mathrm{I} /}$ \\
$\left(\mathrm{g} \mathrm{dm}^{-3}\right)$ & $\left(\mathrm{maCl}_{2}\right)$ & \multicolumn{6}{|c|}{$\mathrm{mmol}_{\mathrm{C}} / \mathrm{dm}^{3}$} \\
\cline { 5 - 9 } & & & $\mathrm{K}^{+}$ & $\mathrm{Ca}^{++}$ & $\mathrm{Mg}^{++}$ & $\left(\mathrm{H}^{+}+\mathrm{Al}^{+3}\right)$ & $\mathrm{CTC}$ & $\mathrm{V}$ \\
\hline 28 & 5,1 & 11 & 2,2 & 33 & 12 & 23 & 69 & 68 \\
\hline
\end{tabular}

1/ Método da resina (Raij \& Quaggio, 1983). 
Tabela 2 - Índice de velocidade de germinação (IVG) e altura de plântulas de soja (cm) para os diferentes períodos de avaliação. UNESP/Botucatu-SP, 2000

\begin{tabular}{|l|c|c|c|c|c|}
\hline \multicolumn{1}{|c|}{ Tratamento } & IVG & 5 DAE & 10 DAE & 15 DAE & 20 DAE \\
\hline Palha na superfície + Irrigação superficial (T1) & $7,46 \mathrm{~b}$ & $6,27 \mathrm{~b}$ & $10,69 \mathrm{~b}$ & $14,78 \mathrm{a}$ & $16,07 \mathrm{a}$ \\
\hline Palha na superfície + Irrigação subsuperficial (T2) & $11,57 \mathrm{ab}$ & $7,56 \mathrm{a}$ & $12,03 \mathrm{ab}$ & $16,69 \mathrm{a}$ & $17,86 \mathrm{a}$ \\
\hline Palha incorporada + Irrigação superficial (T3) & $13,45 \mathrm{a}$ & $5,98 \mathrm{~b}$ & $11,71 \mathrm{ab}$ & $15,31 \mathrm{a}$ & $16,57 \mathrm{a}$ \\
\hline Testemunha sem cobertura (T4) & $12,97 \mathrm{ab}$ & $6,67 \mathrm{ab}$ & $12,84 \mathrm{a}$ & $16,79 \mathrm{a}$ & $18,21 \mathrm{a}$ \\
\hline CV (\%) & 31,56 & 16,97 & 12,94 & 13,24 & 18,94 \\
\hline DMS & 5,53 & 1,24 & 1,69 & 2,32 & 3,59 \\
\hline
\end{tabular}

Valores seguidos de mesma letra na mesma coluna não diferem entre si pelo teste de Tukey a $5 \%$.

DAE - dias após emergência.

Tabela 3 - Índice de velocidade de germinação (IVG) e altura de plântulas de amendoim-bravo (cm) para os diferentes períodos de avaliação. UNESP/Botucatu-SP, 2000

\begin{tabular}{|l|c|c|c|c|c|}
\hline \multicolumn{1}{|c|}{ Tratamento } & IVG & 5 DAE & 10 DAE & 15 DAE & 20 DAE \\
\hline Palha na superfície + Irrigação superficial (T1) & $28,84 \mathrm{a}$ & $7,51 \mathrm{a}$ & $11,06 \mathrm{a}$ & $13,14 \mathrm{a}$ & $15,00 \mathrm{a}$ \\
\hline Palha na superfície + Irrigação subsuperficial (T2) & $36,61 \mathrm{a}$ & $7,88 \mathrm{a}$ & $11,76 \mathrm{a}$ & $15,14 \mathrm{a}$ & $15,86 \mathrm{a}$ \\
\hline Palha incorporada + Irrigação superficial (T3) & $25,58 \mathrm{a}$ & $7,91 \mathrm{a}$ & $10,79 \mathrm{a}$ & $15,14 \mathrm{a}$ & $16,57 \mathrm{a}$ \\
\hline Testemunha sem Cobertura (T4) & $25,51 \mathrm{a}$ & $8,60 \mathrm{a}$ & $12,30 \mathrm{a}$ & $15,93 \mathrm{a}$ & $19,07 \mathrm{a}$ \\
\hline CV (\%) & 25,71 & 20,39 & 19,36 & 21,12 & 26,37 \\
\hline DMS & 11,67 & 1,79 & 2,45 & 3,46 & 4,84 \\
\hline
\end{tabular}

Valores seguidos de mesma letra na mesma coluna não diferem entre si pelo teste de Tukey a 5\%.

DAE - dias após emergência.

a qual não apresentou diferença significativa em relação às associações dos manejos de palha + irrigação, desenvolvidos com os diferentes tratamentos. Com relação à altura de plântulas (Tabelas 2 e 3), a cultura da soja apresentou redução significativa para o T1 apenas nos períodos de 5 e $10 \mathrm{DAE}$; esse efeito já não apresentava diferença significativa, para as espécies estudadas, a partir dos 15 DAE.

Em se tratando do teor de clorofila das folhas de soja, não foram constatadas diferenças significativas entre os tratamentos estudados aos 5, 10, 15 e 20 DAE (Tabela 4).

Com base nos resultados obtidos na análise de crescimento da soja, pode-se observar que os diferentes sistemas de manejo de palhada de capim-braquiária não tiveram influência na área foliar da cultura até os 20 DAE (Figura 1). Para produção de matéria seca, pode-se constatar que a incorporação da palhada ao solo (T3) proporcionou redução significativa das plântulas de soja em relação à testemunha (T4) apenas aos $15 \mathrm{DAE}$, não sendo significativa para os demais tratamentos. No entanto, essa informação não pode ser consolidada em função da razão de área foliar (RAF), a qual se apresentou semelhante para todos os tratamentos e épocas.

Ao isolar os parâmetros matéria seca e área foliar da soja, observa-se que aos $20 \mathrm{DAE}$ a testemunha (T4) e o manejo da palhada superficial + irrigação subsuperficial (T2) apresentaram respectiva tendência de superioridade em relação aos demais manejos avaliados, apesar de todos os tratamentos serem estatisticamente semelhantes.

Quanto aos valores de taxa de crescimento absoluto (TCA) e relativo (TCR) das plântulas de soja (Figura 2), através do ajuste satisfatório das curvas de análises de regressão polinomial 
quadrática para os sistemas T1, T2 e T4 e linear para o sistema T3, podem-se constatar apenas diferenças significativas aos 15 DAE. Como esses parâmetros avaliam a velocidade de crescimento e o acúmulo de matéria seca produzida no tempo, observa-se que aos $15 \mathrm{DAE}$ a incorporação da palhada de capim-braquiária ao solo (T3) proporcionou redução média da TCA e TCR das plântulas de soja em 0,97 e 0,85 vezes, respectivamente, quando comparado com a palhada superficial + irrigação superficial (T1) e palhada superficial + irrigação subsuperficial (T2), e, com relação à testemunha (T4), em 1,79 e 1,43 vezes, respectivamente. Aos 20 DAE, as associações de manejo de palha + irrigação (T1, T2 e T3) apresentaram niveis praticamente semelhantes aos da testemunha (T4) para os parâmetros TCA e TCR das plântulas de soja.

Os dados de taxa assimilatória líquida (TAL) das plântulas de soja mostraram comportamento semelhante aos obtidos em TCA e TCR (Figura 2), nos quais aos $15 \mathrm{DAE}$ foram constados, para o T3, os menores índices de TAL em relação aos demais tratamentos. No entanto, aos 10 DAE os tratamentos T3 e T1 foram, respectivamente, superiores ao T2 e testemunha (T4). Dessa forma, considerando a TAL como a estimativa da eficiência fotossintética, pode-se inferir que a palhada de capimbraquiária incorporada ao solo (T3) proporcionou evidente redução na eficiência da TAL aos 15 DAE, quando comparado aos demais tratamentos. A variação do comportamento da TAL das plântulas de soja apresentou efeitos minimizados entre os tratamentos a partir dos 20 DAE, uma vez que a razão de área foliar (RAF), considerada a área útil para produção de matéria seca, apresentou um ponto ótimo aos 15 DAE (Figura 1), seguido de decréscimo de seus valores em função do auto-sombreamento. Souza et al. (1999) constataram resultados semelhantes, evidenciando redução do teor de $\mathrm{N}$-mineral do solo e no acúmulo de matéria seca de folhas e caules das plantas de soja, em virtude da incorporação da palhada de capim-braquiária ao solo em duas épocas sazonais de coleta.

Para as plântulas de amendoim-bravo, o parâmetro matéria seca (Figura 3) não evidenciou diferenças significativas entre os diferentes manejos de palhada de capim-braquiária e testemunha (T4). Entretanto, em relação à área foliar, pode-se observar significativa redução deste parâmetro para a infestante aos 5 e $10 \mathrm{DAE}$, quando comparado o sistema $\mathrm{T} 1 \mathrm{com}$ os demais tratamentos. Aos 15 e $20 \mathrm{DAE}$, todos os tratamentos não apresentaram diferenças significativas para área foliar e matéria seca do amendoim-bravo. Para a razão de área foliar (RAF), as plântulas de amendoim-bravo submetidas à condição da palhada incorporada ao solo (T3) mostraram-se significativamente superiores aos demais tratamentos aos $5 \mathrm{DAE}$ e, principalmente, aos 10 DAE (Figura 3); esse comportamento foi diferente do observado para cultura da soja, em que não foi constatada diferença entre os tratamentos nos períodos estudados.

Para TCA das plântulas de amendoim-bravo (Figura 4), nos sistemas T1 e T3 as curvas de regressão ajustaram-se satisfatoriamente ao modelo de regressão linear, diferentemente dos sistemas T2 e T4, os quais tiveram suas respectivas equações ajustadas ao modelo de regressão polinomial quadrático, evidenciando

Tabela 4 - Teor de clorofila médio $\left(\mathrm{g} \mathrm{dm}^{-2}\right)$ em plântulas de soja para os diferentes períodos de avaliação. UNESP/BotucatuSP, 2000

\begin{tabular}{|l|c|c|c|c|}
\hline \multicolumn{1}{|c|}{ Tratamento } & $5 \mathrm{DAE}$ & $10 \mathrm{DAE}$ & $15 \mathrm{DAE}$ & $20 \mathrm{DAE}$ \\
\hline Palha na superfície + Irrigação superficial (T1) & $3,27 \mathrm{a}$ & $4,18 \mathrm{a}$ & $3,67 \mathrm{a}$ & $4,13 \mathrm{a}$ \\
\hline Palha na superfície + Irrigação subsuperficial (T2) & $3,32 \mathrm{a}$ & $4,18 \mathrm{a}$ & $3,64 \mathrm{a}$ & $4,37 \mathrm{a}$ \\
\hline Palha incorporada + Irrigação superficial (T3) & $3,72 \mathrm{a}$ & $4,32 \mathrm{a}$ & $3,59 \mathrm{a}$ & $4,15 \mathrm{a}$ \\
\hline Testemunha sem cobertura (T4) & $3,23 \mathrm{a}$ & $4,11 \mathrm{a}$ & $3,61 \mathrm{a}$ & $3,91 \mathrm{a}$ \\
\hline CV (\%) & 9,69 & 5,18 & 10,06 & 8,31 \\
DMS & 0,49 & 0,33 & 0,55 & 0,52 \\
\hline
\end{tabular}

Valores seguidos de mesma letra na mesma coluna não diferem entre si pelo teste de Tukey a 5\%.

DAE - dias após emergência. 
ótimo de crescimento aos $15 \mathrm{DAE}$; o mesmo comportamento foi observado para a cultura da soja. Dessa forma, aos 15 DAE, os sistemas de manejo T1 e T3 promoveram respectiva redução no crescimento do amendoim-bravo de 0,22 e 0,27 vezes, em relação à testemunha (T4). Aos 20 DAE, apenas a TCA do sistema T1 superou os demais tratamentos, mas não atingindo amplitudes representativas semelhantes com relação a TCR (Figura 4), em que todas as equações dos diferentes sistemas de manejo ajustaram-se satisfatoriamente ao modelo de regressão polinomial quadrático. Para a variável taxa assimilatória líquida (TAL) das plântulas de amendoim-bravo (Figura 4), observa-se que apenas o sistema de manejo $\mathrm{T} 1$ apresentou niveis ligeiramente superiores aos dos demais tratamentos aos 10 e $20 \mathrm{DAE}$; aos $15 \mathrm{DAE}$ o maior destaque em eficiência fotossintética foi representado pelo sistema T2.
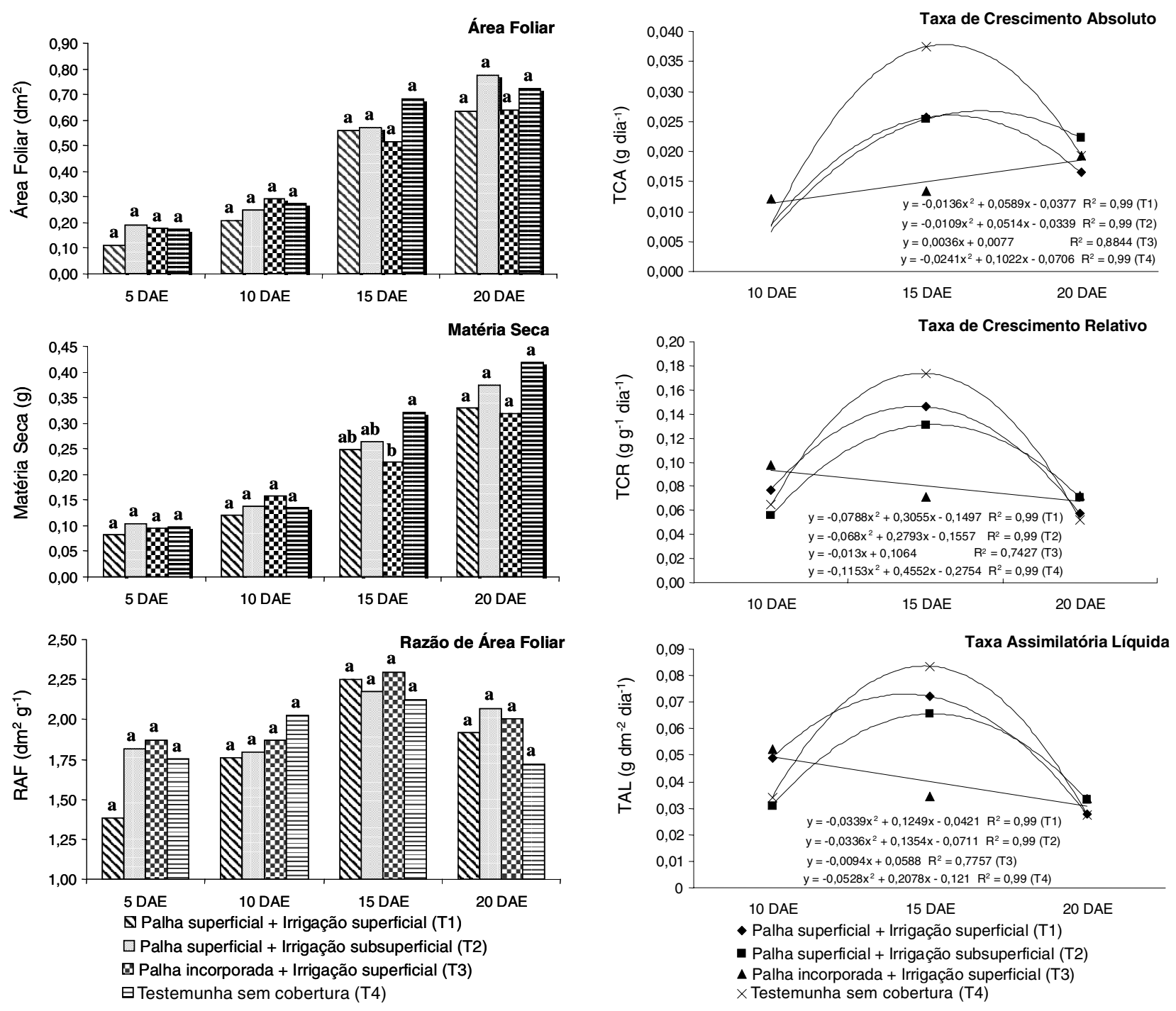

Figura 1 - Variáveis área foliar, matéria seca e razão da área foliar das plântulas de soja em função das épocas de avaliação, submetidas aos diferentes tratamentos. Valores seguidos de mesma letra na mesma coluna não diferem entre si pelo teste de Tukey a 5\%.

Figura 2 - Equações de regressão da taxa de crescimento absoluto, relativo e assimilatória líquida das plantas de soja em função das épocas de avaliação, submetidas aos diferentes tratamentos. 

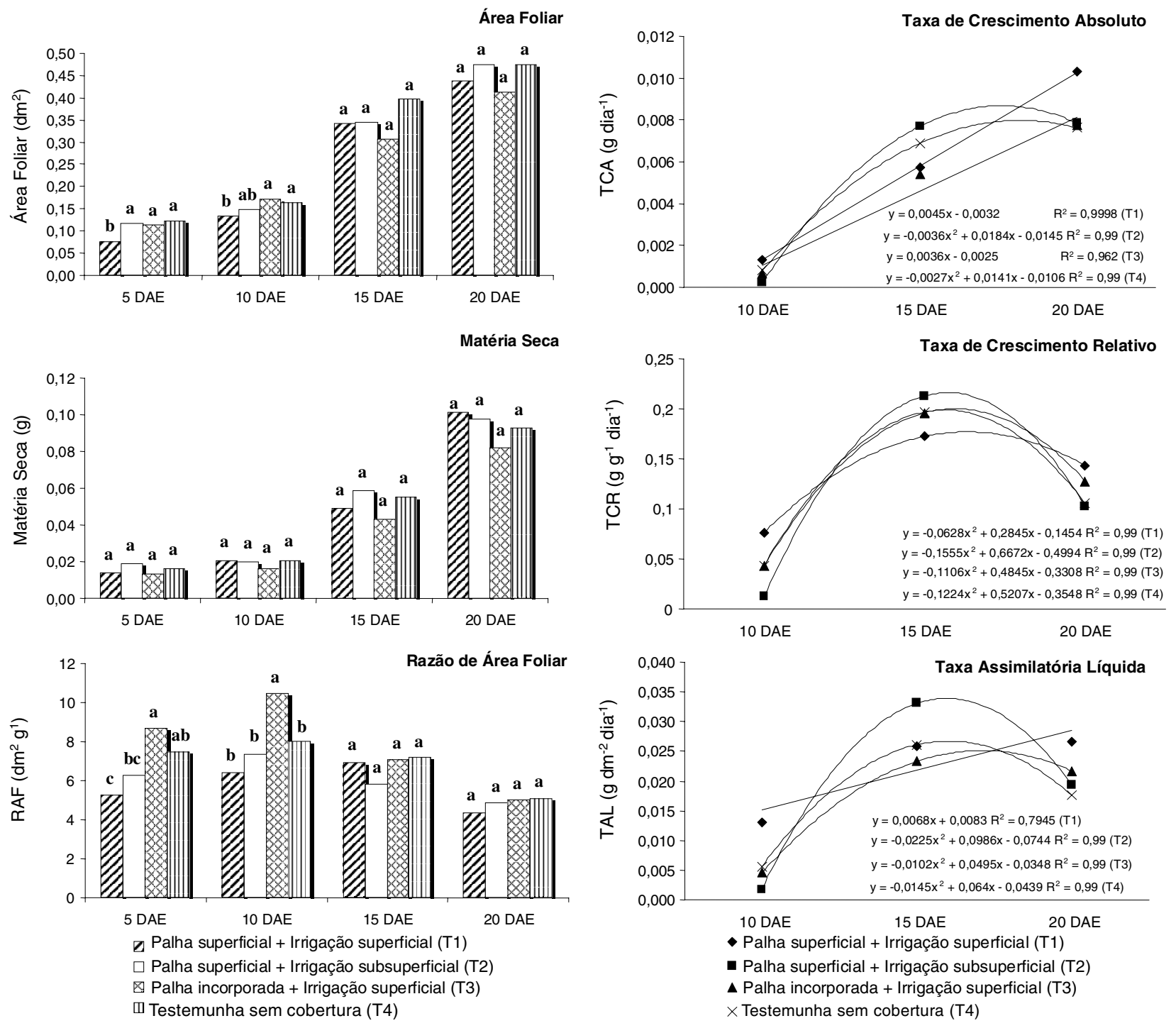

Figura 3 - Variáveis área foliar, matéria seca e razão da área foliar das plantas de amendoim-bravo em função das épocas de avaliação, submetidas aos diferentes tratamentos. Valores seguidos de mesma letra na mesma coluna não diferem entre si pelo teste de Tukey a $5 \%$.

De forma geral, as plântulas de soja e amendoim-bravo apresentaram comportamento semelhante com relação aos tratamentos avaliados para os parâmetros altura de plantas e matéria seca, não havendo destaques significativos, principalmente, para os períodos de 5 e $10 \mathrm{DAE}$. Contudo, por meio do índice de velocidade de germinação (IVG), pode-se observar que, ao contrário da soja, a planta daninha amendoim-bravo não sofreu

interferência na capacidade de germinação quando submetida à presença da palhada de capim-braquiária superficialmente ou incorporada ao solo. Esses resultados concordam com os obtidos por Martins et al. (1999), em que quantidades crescentes de palha de cana-deaçúcar geradas em sistema de cana crua não interferiram na emergência de amendoimbravo. Seifert \& Voll (2000) observaram resposta semelhante em sistema de semeadura direta 
da soja, em que a taxa média de emergência de amendoim-bravo apresentou-se mais decrescente e inferior em número na ausência do que na presença de cobertura morta de aveia-preta. Assim, o amendoim-bravo deverá continuar sendo considerado planta-problema para sistemas de produção com palha.

A taxa de crescimento absoluto (TCA), a taxa de crescimento relativo (TCR) e a taxa assimilatória líquida (TAL) das plântulas de soja e amendoim-bravo apresentaram niveis máximos aos $15 \mathrm{DAE}$, apesar do evidente desempenho negativo no desenvolvimento das plântulas de soja para o tratamento com palhada de capim-braquiária incorporada ao solo, em relação aos demais tratamentos.

Assim, a menor eficiência do sistema T3 pode ser caracterizada pela provável hipótese de produção de aleloquímicos, resultante da decomposição da palha de capim-braquiária incorporada ao solo. Por outro lado, o tratamento com palhada na superfície do solo + irrigação superficial não promoveu o mesmo comportamento, desmistificando o favorecimento de processo semelhante através da lixiviação de compostos presentes na palhada via irrigação superficial, uma vez que o efeito foi praticamente idêntico ao do tratamento com palhada na superfície do solo + irrigação subsuperficial, o qual não prejudicou o desenvolvimento da cultura. Além disso, deve-se ressaltar a importância de considerar a interação dos possiveis efeitos alelopáticos e a competição por nitrogênio entre plantas e microrganismos, principalmente quando se trabalha com resíduos culturais de elevada relação C:N, como a de espécies gramíneas.

\section{LITERATURA CITADA}

ALMEIDA, F.S. et al. Efeitos alelopáticos e de competição da B. plantaginea na soja. In: CONGRESSO BRASILEIRO DE HERBICIDAS E PLANTAS DANINHAS, 16., 1986, Campo Grande. Resumos... Campinas: SBHED, 1986. p. 5-6.

ALMEIDA, F. S. A alelopatia das plantas. Londrina: IAPAR, 1988. 60 p. (IAPAR, Circular, 53).

BELL, D. T.; KOEPPE, D. E. Noncompetitive effects of giant foxtail on the growth of corn. Agron. J., v. 64, p. 321325, 1972.

DURIGAN, J. C.; ALMEIDA, F. L. S. Noções sobre alelopatia. Jaboticabal: FUNEP, 1993. 28 p.

Planta Daninha, Viçosa-MG, v.21, n.3, p.365-373, 2003
GRESSEL, J. B.; HOLM, L. G. Chemical inhibition of crop germination by weed seed and the nature of the inhibition by Abutilon theophrasti. Weed Res., v. 4, p. 44-53, 1964.

GUENZI, W. D. et al. Presence and persistence of phytotoxic substances in wheat, oat, corn and sorghum residues. Agron. J., v. 59, p. 163-166, 1967.

MAGUIRE, J. D. Speeds of germination-aid selection and evaluation for seedling emergence and vigor. Crop Sci., v. 2, p. $176-177,1962$.

MARTINS, D. et al. Emergência em campo de dicotiledôneas infestantes em solo coberto com palha de cana-de-açúcar. Planta Daninha, v. 17, n. 1, p. 151-161, 1999.

McCALLA, T. M.; HASKINS, F. A. Phytotoxic substances from microrganisms and crop residues. Bacteriol. Ver., v. 28, p. 181-207, 1964.

McCALLA, T. M.; NORSTADT, F. A. Toxicity problems in mulch tillage. Agric. Environ., v. 1, p. 153-174, 1974.

MULLER, C. H. The role of chemical inhibition (allelopathy) in vegetation composition. Bull Torrey Bot. Club., v. 93, p. 332-351, 1966.

PATRICK, Z. A. Phytotoxic substances associated with decomposition in soil of plants residues. Soil Sci., v. 111, p.18-28, 1971.

PATRICK, Z. A.; TOUSSON, T. R. Plant residues and organic amendments in relation to biological control. In: BAKER, K. E. E.; SYNDER, W. C. (Eds.) Ecology of soilborne pathogens. Berkeley: University of California, 1965. p. $440-450$.

PATRICK, Z. A. et al. Effects of crop-residue decomposition products on plant roots. Ann. Ver. Phytopathol., v. 2, p. 267-292, 1964.

RAIJ, B. V.; QUAGGIO, J. A. Método de análise de solo para fins de fertilidade. Bol. Tec. Inst. Agron. Campinas, n. 81 , p. $1-31,1983$.

RAMOS, M. B. M.; VALENTE, T. O. Interferência de substâncias alelopáticas extraídas de Brachiaria decumbens Stapf. na germinação da soja (Glycine max) e milho (Zea mays). In: CONGRESSO BRASILEIRO DA CIÊNCIA DAS PLANTAS DANINHAS, 21., 1997, Viçosa, MG.

Resumos... Viçosa: Sociedade Brasileira da Ciência das Plantas Daninhas, 1997. p. 438.

RICE, E. L. Allelopathy. 2.ed. New York: Academic Press, 1984. $422 \mathrm{p}$.

SEIFERT, G.; VOLL, E. Cobertura de aveia e calagem sobre amendoim-bravo em semeadura direta de soja. Planta Daninha, v. 18, n. 2, p. 309-322, 2000. 
SOUZA, L. S. et al. Efeitos alelopáticos de Brachiaria decumbens Stapf. sobre o desenvolvimento inicial da soja (Glycine max L.). In: CONGRESSO BRASILEIRO DE SOJA, 1999, Londrina, PR. Anais... Londrina: EMBRAPA Soja, 1999. p. 415. (EMBRAPA Soja Documentos, 124).
VELINI, E. D.; NEGRISOLI, E. Controle de plantas daninhas em cana crua. In: CONGRESSO BRASILEIRO DA CIÊNCIA DAS PLANTAS DANINHAS, 22., 2000, Foz do Iguaçu, PR. Palestra... Foz do Iguaçu: Sociedade Brasileira da Ciência das Plantas Daninhas, 2000. p. $148-164$. 